\title{
A Preliminary Investigation of Chinese Tourists in Berlin
}

$$
\text { TANG Zia }{ }^{a},{ }^{\star} \text { ZHANG Peiyin }{ }^{b}, \text { BI Jun }{ }^{c} \text {, QIU Zeguo }{ }^{d}
$$

School of Tourism and Cuisine, Harbin University of Commerce, Harbin, China

Email: atz09@163.com, b1304695178@qq.com, c51045432@qq.com, d40216735@qq.com

Keywords: Chinese tourists, preliminary investigation, Berlin.

\begin{abstract}
Outbound tourism has become a popular choice for Chinese tourists. Due to duty free for shopping, relaxed restrictions of passport or visa, etc., Germany has been one of tourism destinations. This paper carried out a preliminary investigation on Chinese tourists traveling Berlin, and analyzed their travel purposes, tourist's age, occupation and education background, source of tourists, travel pattern, travel time, and so on, which can provide reference for outbound tourism development.
\end{abstract}

\section{Introduction}

Along with the improvement of living standards and the increase of leisure time, the consumption levels of Chinese peoples are rapidly rising. Outbound tourism has become a popular choice for Chinese tourists. Seen from the Chinese tourists, the continent of Europe resembles not so much an ancient collection of cities and architectures as a glittering emporium stocked with brands. In addition, a series of positive factors, such as the falling of exchange rate of euro against the RMB, duty free for shopping, and relaxed restrictions of passport or visa, directly stimulate the European long-term tourism market. In European countries, France, Switzerland and Italy are the major destination for Chinese tourists.

\section{Chinese Tourists in Germany}

According to a report published by China Tourism Academy, the German tourism market is growing rapidly. The high quality hotels, Michelin-star restaurants, travel car rental and tax-free shopping in Germany are the important factors to attract Chinese tourists. From the national policy level, it is also another important reason that German Government provide convenient for Chinese tourists by changing visa policy. In October 2014, China and Germany signed a bilateral agreement, "finished visa within 48 hours", which played a great role in promoting tourism development. In addition, in order to attract more Chinese tourists, Germany increase tourism promotion among the Chinese people and launch various marketing campaigns to suit Chinese tourists. In the meantime, German National Tourist Office has registered micro-blog or micro-chat in China and publishes tourism information for the Chinese people, so that more Chinese people understand Germany and know Germany. Moreover, German National Tourist Office provides a lot of Chinese information in tourism websites, such as http://www.germany.travel/cn/index.html, http://laibolin.com/index.php, which play a very important role to introduce German tourism resources to the Chinese peoples.

According to the German National Tourism Board, the number of Chinese tourists in Germany reached 1.39 million person times, a year-on-year increase of 34.8 per cent. From January to August 2016 the number of overnights by Chinese citizens in Germany alone rose to 1,681,000. China has become one of important tourism markets of inbound tourism in Germany, ranked 13th in all the tourist markets. According to the world's biggest drawback service--global blue data, Chinese tourists are spending the most money in Germany in the first quarter of 2014, per capita consumption of 575 euros. The increasingly development of Chinese middle class make China become the most powerful market for Germany inbound tourism. 


\section{A Survey on Chinese Tourists Traveling Berlin}

Berlin is rich in tourism products with abundant history, culture, art resources, which makes Berlin as favorite destination for Chinese tourists. Berlin is regarded as one of environmentally-friendly cities in Europe. From the bird's eye view, Berlin is surrounded by forests, lakes, rivers, as if it immersed in a green sea. In Berlin, there are many cultural relics and historic sites, magnificent modern building, the Berlin Wall through the ages, and the world-famous universities, which are enough to attract the arrival of Chinese tourists. According to a survey on Chinese tourists traveling Berlin,

The Way to Know about Berlin before Traveling: Introduction from friends or family, travel agency, internet and other new media, film or literary works. In China, there is a lot of information about German education, society, economy and "Made in Germany". Therefore, many Chinese people are interesting in Germany.

Travel Purposes: Sightseeing, leisure vacation, business trip, visiting relatives and friends, education, learning exchange, shopping, and so on. Mainly are cultural sightseeing and shopping.

Tourism Attractions: Most Chinese tourists traveling to Germany choose Frankfurt am Main as a distributing center and destination, and a small number of them choose Berlin as a transit area. Because the time is limited, they given priority to half-day or one-day trip in Berlin.

Half-day Route: Brandenburg Gate, Victory Column, Germany's national Memorial for the Murdered Jews of Europe, Reichstag building, Unter den Linden Avenue, Humboldt University of Berlin, Berlin cathedral, Museum Island, East Side Gallery, Berlin's television tower, Alexanderplatz, and so on;

One-day Route: also including Berliner Rathaus, Gendarmenmarkt, Jüdisches Museum Berlin, Checkpoint Charlie, Potsdamer Platz, Zoologischer Garten, and so on;

Two-day Route: also including Charlottenburg Palace, Berlin Olympiastadion, Potsdam's Gardens, Outlets, and so on.

Tourist's Age: Most of them aged from 20 to 29, 30 to 44, 45 to 59, and more than 60 years old.

Occupation and Education Background: The tourists are made up of students, most of that are studying in Germany and the other countries of Europe; staffs that work in enterprises and institutions, retirees, or non-working persons. The tourists with three years at college, four years at university and a postgraduate degree account for a large proportion.

Source of Tourists: Chinese tourists mainly come from the developed economic region in eastern China, such as the regions of Beijing, Tianjin and Hebei Province, the Yangtze River Delta region including Shanghai, Nanjing, Hanzhou, etc., the Pearl River Delta region including Guangzhou, Shenzhen, Zhuhai, etc.. The tourist numbers from second-tier Chinese cities, such as Chengdu, Chongqing, Xi'an, Qingdao, Kunming, Wuhan, Xiamen, are also increasing. In addition, there are some Ethnic Chinese tourists from Hong Kong, Macao, Taiwan, America, Canada, Australia, and European countries.

Travel Pattern: Package tour, independent travel, or road trip.

The tourists with a tour group mainly come from within China. Aged from 25 to 50, they travel in Europe using their vacation or taking advantage of their work, focused on summer holiday (June, July and August) or winter holiday (January and February), and some official holiday of China (such as during the Spring Festival, the National Holiday). Aged about 60 years old, they are retired and have plenty of times to travel around, so there is no time limit on the trip to Berlin or Europe for them.

For traveling independently or road trip, one part of tourists come from within China, aged from 30 to 45, they travel in Europe on their vocation. The other part is students studying in Germany and the other European countries, they travel around during holidays. Another part is ethnic Chinese working or living in Germany, including visiting scholars.

Travel Time: Summer is the peak tourism season to Berlin, concentrated in June, July and August. During this period also is the Chinese student's summer vacation, so there are relatively larger students among the tourists. In China, July and August are always the outbound 
tourism season. Because this period is throughout the summer holiday, it is the first choice for the family to travel overseas and investigate tourism before studying abroad.

At the end of September and the beginning of October, there are the Chinese traditional Mid-Autumn festival and the National Day of China. In this period people have seven-day holiday at least, which causes one peak period of tourism. For instance, in 2015, 27th September is the Mid-Autumn festival, and there are 2-day holidays (9.26-27); 1th October is the National Day of China, and there are 7-day holidays (10.1-7). There are only 3 days between the Mid-Autumn festival and the National Day, so about 12-day holidays for Chinese peoples, which formed a tourism boom of "Mid-Autumn festival + National Day" holidays.

In January and February, there is the winter holiday for Chinese students, and there is also one of important Chinese traditional festivals - the Spring Festival. So some people will go to travel in Germany and the other countries.

Tourists in Berlin: They can spend one day walking along the old streets or walking around Berlin's historic center, admiring the classical architectures, and tracing the many layers of history and culture.

They eat Berlin's amazing food, such as currywurst, Döner, Pizza, sandwich, all sorts of bier, sausage, bread, caffee......

They praise the convenient transportation; U-bahn, S-bahn, and bus are frequent and punctual.

Shopping is also important for Chinese tourists. They purchase luxuries and other everyday items in Alexanderplatz, Friedrichstrasse, Kaufhaus des Westens, Potsdamer Platz, Outlets, DM, Rossmann, and so on.

Tourists' Feeling for Berlin: Berlin is a both old and modern city. It is full of historical and cultural sense meanwhile is rich spirit of the time. Picturesque natural scenery, rich cultural and artistic atmosphere, all shapes roof of the palaces and churches, unique style of European architecture and humanistic customs, and infinite shopping opportunities, constitute overall impression of Berlin for the Chinese tourists.

\section{Problems and Suggestions}

Berlin's many attractions can be freely visited, or can be appreciated from the appearance, which is more popular for Chinese tourists. However, the introduction or explanations of most scenic spots only are in German and English. For Asian countries, some scenic offer Japanese or Korean introduction. With an increasing number of Chinese tourists, it is suggested that the Chinese service should be supplied in scenic spots, restaurants, and shopping mall, in order to better meet the Chinese tourists' understanding of German related content.

\section{Acknowledgement}

This research was financially supported by China Postdoctoral Science Foundation (Grant NO. 2016M600257), Postdoctoral program of Heilongjiang Province (Grant NO. LBH-Z16093), Project of philosophy and social sciences Heilongjiang Province (Grant NO. 16JYE03), Doctoral research project of Harbin University of Commerce (Grant NO. 2016BS05), support project of young innovative talents of Harbin University of Commerce (Grant NO. 2016QN028), and Discipline project of Harbin University of Commerce: Study on the modern service industry to support Longjiang revitalization (Grant NO. hx2016001).

\section{References}

[1] http://travel.sohu.com/20150829/n420049629.shtml

[2] http://www.germany.travel/cn/index.html

[3] http://laibolin.com/index.php 